\title{
PENINGKATAN PENDAPATAN NELAYAN TRADISIONAL MELALUI PENDAMPINGAN MANAJEMEN PENGOLAHAN DAN PENGAWETAN IKAN PADA ISTRI NELAYAN DI KELURAHAN KEDUNGCOWEK, KECAMATAN KENJERAN, SURABAYA
}

\section{INCREASING INCOME OF TRADITIONAL FISHERMEN THROUGH MANAGEMENT ASSISTANCE IN FISH PROCESSING AND PRESERVATION FOR FISHERMEN'S WIFE IN KEDUNGCOWEK KENJERAN SURABAYA}

\author{
Wasiaturrahma $^{1}$, Dina Heriyati ${ }^{2}$, Chorry Sulistyowati ${ }^{3}$, Shochrul Rohmatul Ajija ${ }^{4}$, \\ Tita Novita Sari ${ }^{5}$ \\ ${ }^{1,4}$ Departemen Ilmu Ekonomi, Fakultas Ekonomi dan Bisnis, Universitas Airlangga \\ ${ }^{2}$ Departemen Akuntansi, Fakultas Ekonomi dan Bisnis, Universitas Airlangga \\ ${ }^{3}$ Departemen Manajemen, Fakultas Ekonomi dan Bisnis, Universitas Airlangga \\ ${ }^{5}$ Koperasi BMT Mandiri Ukhuwah Persada, Jawa Timur \\ email: shochrul-r-a@ feb.unair.ac.id
}

\begin{abstract}
The income of fishermen in Kelurahan Kedungcowek, Kenjeran District, Surabaya City is relatively low. Thus, it requires the role of a wife to help meet family needs. This activity aims to provide management assistance for fish processing and preservation to fishermen's wives in Kedungcowek village in order to increase the selling value of fish. This activity uses the action research method. The result of this activity is an increase in the abilities and skills of fishermen's wives in increasing the selling value of fish. The income of the Kedungcowek fishermen's family has increased more from the existence of this community service activity.
\end{abstract}

Keywords: Fishermen's Income, Fishermen's Wife, Kedungcowek

\section{abstrak}

Pendapaan nelayan di Kelurahan Kedungcowek, Kecamatan Kenjeran, Kota Surabaya, relatif rendah. Sehingga, membutuhkan peran seorang Istri untuk membantu memenuhi kebutuhan keluarga. Kegiatan ini bertujuan untuk melakukan pendampingan manajemen pengolahan dan pengawetan ikan pada istri nelayan di kelurahan Kedungcowek dalam rangka meningkatkan nilai jual ikan. Kegiatan ini menggunakan metode action research. Hasil dari kegiatan ini yaitu peningkatan kemampuan dan keterampilan para istri nelayan dalam meningkatkan nilai jual ikan. Pendapatan keluarga nelayan Kedungcowek menjadi lebih meningkat dari adanya kegiatan pengabdian masyarakat ini.

Kata Kunci : Istri Nelayan, Kedungcowek, Pendapatan Nelayan

\section{PENDAHULUAN}

Indonesia merupakan negara yang memiliki wilayah laut yang sangat luas yang mengandung potensi ekonomi kelautan yang sangat besar dan beragam (Agustin, dkk., 2017) . Badan Pusat Statistik (BPS) pada tahun 2018, luas wilayah laut di Indonesia yaitu sebesar 3,351 juta $\mathrm{km} 2$ yang terdiri dari sekitar 5,8 juta $\mathrm{km} 2$ wilayah penyebaran daerah penangkapan ikan yang terbagi menjadi 11 Wilayah Pengelolaan Perikanan Negara Republik Indonesia (WPPNRI). Besarnya sumber daya laut yang dimiliki Indonesia, menjadikan profesi nelayan sebagai profesi yang banyak digeluti masyarakat daerah pesisir. Nelayan adalah suatu kelompok masyarakat yang kehidupannya 
Wasiaturrahma, dkk: Peningkatan Pendapatan Nelayan Tradisional Melalui Pendampingan Manajemen Pengolahan dan Pengawetan Ikan Pada Istri Nelayan di Kelurahan Kedungcowek, Kecamatan Kenjeran, Surabaya

tergantung langsung pada hasil laut, baik dengan cara melakukan penangkapan ataupun budidaya (Nurjannah dan Dahrma, 2019).

Kekayaan sumber daya perikanan di Indonesia seharusnya menjadikan profesi nelayan sebagai profesi yang mensejahterahkan keluarga. Namun, di Indonesia masih banyak nelayan yang hidup di bawah garis kemiskinan dilihat dari hasil tangkapan nelayan masih jauh dari memadahi untuk memenuhi kebutuhan hidupnya (Retnowati 2011). Sebagian besar nelayan yang tergolong miskin merupakan nelayan artisanal (kecil) yang memiliki keterbatasan kapasitas penangkapan baik penguasaan teknologi, metode penangkapan. maupun permodalan (Puluhulawa dkk., 2016). Menurut Acheson (1981) dalam (Listyawati 2020) nelayan memiliki dua kendala utama diantaranya yaitu kendala yang menyangkut lingkungan alam yaitu meliputi kondisi laut yang penuh resiko bahaya serta ketidakpastian datangnya ombak besar, hujan deras disertai angin kencang, dan badai, serta biotik laut lain yang beragam. Kendala lainnya yaitu menyangkut lingkungan sosial yaitu terjadi persaingan, baik secara individu maupun kelompok. Masalah kemiskinan nelayan juga disebabkan karena adanya ketimpangan pemanfaatan sumberdaya ikan (Zebua et al. 2017).

Salah satu kelompok nelayan di Indonesia yang memiliki kendala yaitu kelompok nelayan Nambangan. Kampung Nambangan terletak di kelurahan Kedungcowek, Kecamatan Kenjeran, Kota Surabaya (Ulum, dkk., 2020). Kemampuan dalam pengolahan ikan para nelayan di Kedungcowek masih terbatas. Para nelayan di kedungcowek langsung menjual hasil tangkapan ikan ke para tengkulak sehingga harga yang diterima nelayan tergantung dari harga yang ditentukan tengkulak. Para nelayan menjadi belum berdaya untuk bisa mendapatkan harga yang lebih tinggi, padahal harga jual ke konsumen akhir jauh berbeda dari hasil penjualan yang didapatkan nelayan ke para tengkulak dan para nelayan di Kedungcowek memiliki potensi untuk mendapatkan hasil penjualan lebih tinggi dari pada langsung dijual ke para tengkulak.

Pendapatan nelayan di Kedungcowek relatif rendah dan tidak pasti sehingga, membutuhkan peran seorang Istri untuk membantu memenuhi kebutuhan keluarga. Istri nelayan mempunyai andil yang besar dalam mmeningkatkan pendapatan dan mewujudkan kesejahteraan keluarga (Kurniawati 2017). Pengolahan sebagian ikan dan hasil tangkapan laut dilakukan oleh para istri nelayan Kedungcowek lalu dipasarkan secara tradisional dengan kemasan dan kualitas produk seadanya. Padahal jika ikan dan hasil tangkapan laut para nelayan Kedungcowek diolah dengan baik, akan dapat meningkatkan penghasilan. Oleh karena itu, meningkatkan kemampuan istri nelayan dalam mengelola dan memasarkan hasil tangkapan ikan para nelayan merupakan salah satu alternatif solusi dalam meningkatkan nilai jual hasil tangkapan ikan para nelayan di Kedungcowek. Atas dasar latar belakang tersebut maka diadakan kegiatan pengabdian masyarakat yang berjudul "Peningkatan Pendapatan Nelayan Tradisional Melalui Pendampingan Manajemen Pengolahan dan Pengawetan Ikan pada Istri Nelayan di Kelurahan Kedungcowek, Kecamatan Kenjeran, Surabaya”.

\section{METODE PENGABDIAN MASYARAKAT}

Kegiatan pengabdian masyarakat ini dilakukan di daerah Kelurahan Kedungcowek, Kecamatan Kenjeran, Kota Surabaya. Daerah tersebut merupakan daerah yang sebagian 
besar masyarakatnya berprofesi sebagai nelayan karena lokasinyaa dekat dengan pantai Kenjeran. Subjek dalam kegiatan pengabdian masyarakat ini yaitu para Istri Nelayan Kedungcowek. Dara primer dari kegiatan pengabdian masyarakat ini, diperoleh dari hasil wawancara dengan para istri Nelayan di Kelurahan Kedungcowek.

Kawasan nelayan di Kelurahan Kedungcowek membutuhkan peningkatan nilai jual hasi tangkapan laut sehingga dapat menambah pendapatan. Oleh karena itu diadakan penelitian tindakan action research dalam bentuk pendampingan manajemen pengolahan dan pengawetan ikan pada istri nelayan di kelurahan kedungcowek. Metode penelitian tindakan merupakan metode yang terdiri dari empat tahapan yaitu planning, acting, observing, dan reflecting. Berikut adalah penjelasn masing-masing tahapan action research (Sucipto 2016) :

\section{Menyusun perencanaan (planning)}

Pada tahap ini dilakukan beberapa kagiatan penting meliputi persiapan berbagai fasilitas dan sarana pendukung yang dibutuhkan dalam penelitian, kegiatan lainnya yaitu mempersiapkan berbagai instrumen yang digunakan untuk merekam dan menganalisis data mengenai proses dan hasil tindakan.

\section{Melaksanakan tindakan (acting)}

Pada tahap ini peneliti mulai melaksanakan berbagai tindakan yang telah dirumuskan yang terdiri dari kegiatan awal, inti dan penutup dan dilakukan dalam situasi yang aktual.

\section{Melaksanakan pengamatan (observing)}

Pada tahap ini, dilakukan kegiatan pengumpulan data. Tahap ini bertujuan untuk mengumpulkan data pendukung yang dibutuhkan dalam proses penelitian. Pengumpulan data dilakukan dengan cara wawancara dan observasi.

\section{Melakukan refleksi (reflecting)}

Kegiatan yang dilakukan pada tahap ini yaitu mencatat hasil observasi, , menganalisis hasil pembelajaran, mengevaluasi hasil observasi, mencatat berbagai kekurangankekurangan untuk dijadikan bahan penyusunan rancangan sistem pendukung keputusan agar tujuan tercapai.

\section{HASIL DAN PEMBAHASAN}

Pembangunan wilayah Kota Surabaya yang sangat massive dan terstruktur membuat keberadaan nelayan tradisional di Kelurahan Kedungcowek, Kecamatan Kenjeran, Kota Surabaya semakin diperhatikan. Area yang awalnya kumuh dan bau anyir karena masyarakat menjemur ikan asin di sepanjang jalan, sekarang menjadi kawasan yang relative bersih dan tertata. Berbagai program telah dilakukan baik oleh pemerintah, akademisi, maupun pihak swasta untuk meningkatkan kesejahteraan nelayan di kawasan tersebut. Salah satunya adalah dibangunnya Sentra Ikan Bulak (SIB) yang bertujuan untuk memasarkan hasil produk nelayan secara langsung ke masyarakat. Namun demikian, hingga saat ini nelayan di Kedungcowek masih menghadapi beberapa kendala. Skill pengolahan ikan para nelayan di Kedungcowek juga masih terbatas. Sehingga pendapatan yang diperoleh para nelayan relatif rendah. Oleh karena itu kegiatan pengabdian masyarakat ini, melakukan action research dalam bentuk 
pendampingan manajemen pengolahan dan pengawetan ikan pada istri nelayan dalam rangka meningkatkan pendapatan keluarga nelayan di Kelurahan Kedung Cowek. Proses Action Research dalam kegiatan masyarakat ini yaitu :

\section{Penyusunan Rencana dengan Pemerintah Kelurahan Kedungcowek}

Pada tahap ini, pihak Universitas Airlangga sebagai pelaksana, menyampaikan gagasan kepada pemerintah Kelurahan Kedungcowek, meminta persetujuan serta berdiskusi mengenai pelaksanaan kegiatan di lapangan. Pemerintah setempat menyambut dengan baik serta memberikan data keluarga nelayan yang potensial menjadi subjek dalam kegiatan pengabdian ini.

\section{Penyuluhan kepada Para Istri Nelayan}

Kegiatan ini diadakan dalam rangka pengenalan program pengabdian masyarakat ini serta menjelaskan kepada para istri nelayan mengenai pentingnya adanya program ini. Penyuluhan dilakukan oleh pihak Universitas Airlangga dan dihadiri oleh seluruh Istri Nelayan di Kelurahan Kedungcowek yang menjadi subjek dalam kegiatan pengabdian ini.

\section{Pelaksanann Kegiatan}

Terdapat beberapa tahapan pelaksanaan program pengabdian masyarakat ini. Hal ini tampak pada diagram alur berikut:

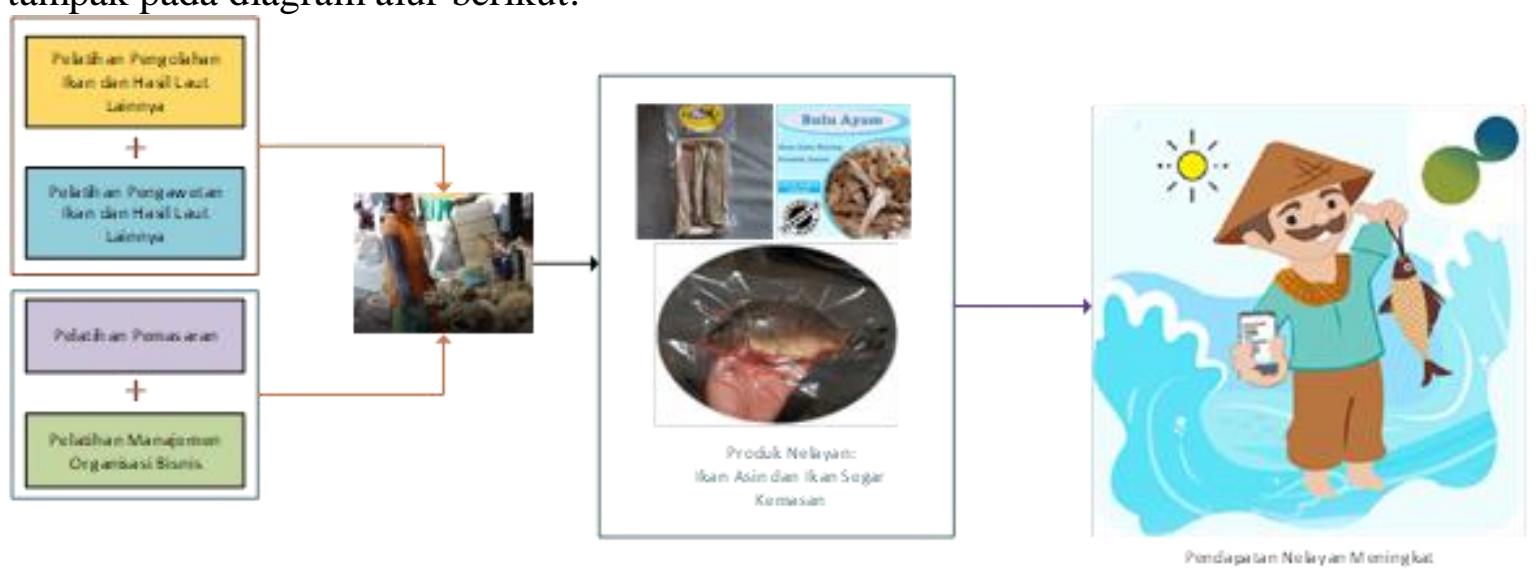

\section{Gambar 1. Tahapan Pelaksanaan Kegiatan}

Secara lebih detail, tahapan pelaksanaan kegiatan pengabdian masyarakat ini adalah sebagai berikut:

\section{Pelatihan Tahap 1}

Pada tahap ini, tim pengabdian masyarakat bekerjasama dengan mitra yang telah ahli dalam mengolah dan mengawetkan ikan serta hasil laut lainnya yaitu tim ahli dari Lembaga Swadaya Masyarakat (LSM) Wahana Lingkungan Hidup Indonesia (WALHI). Saat ini, kelompok nelayan telah memiliki freezer ukuran 200 liter. Dengan demikian, tujuan dari pelatihan ini adalah agar nelayan mampu mengolah ikan dengan baik dan bisa memanfaatkan freezer yang mereka miliki untuk pengawetan produk. Selain itu pada tahap ini, dilakukan penyerahan mesin Vacuum Sealer. Vacuum sealer adalah sebentuk mesin packaging yang mempunyai dua fungsi untuk dijalankannya, 
yaitu fungsi untuk menyedot oksigen dari dalam kantong kemasan dan sekaligus fungsi untuk menyegel kantong kemasan itu sendiri (Agusti and Wasisto 2019). Mesin ini sangat bermanfaat untuk membantu para istri nelayan mengaplikasikan materi di pelatihan ke dalam produk-produknya. Sehingga dapat meningkatkan nilai jual produk dan pendapatan keluarga nelayan semakin meningkat

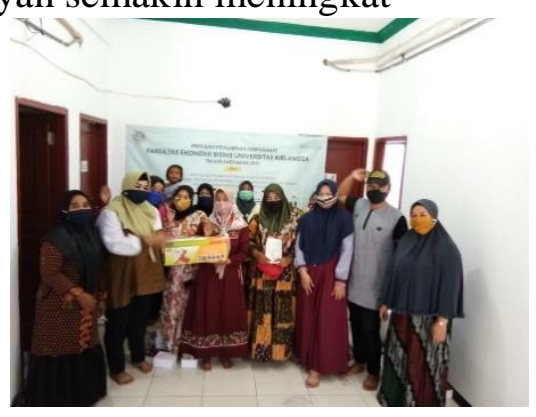

\section{Gambar 2 Penyerahan Mesin Vacum Sealer}

\section{Pelatihan Tahap 2}

Pada tahap ini, tim pengabdian masyarakat mengkoordinir kelompok nelayan dan melatih strategi pemasaran produk baik secara offline maupun online, serta melatih manajemen usaha yang baik. Pada tahap ini, tim pengabdian masyarakat juga membantu meningkatkan kualitas pengemasan produk-produk yang dihasilkan oleh para istri nelayan. Kemasan merupakan salah satu cara untuk mempromosikan produk serta menarik minat konsumen untuk membeli suatu produk (Harminingtyas 2013). Selain itu fungsi pengemasan pada makanan yaitu untuk melindungi makanan dari kontaminasi yang dapat mengganggu, merugikan serta membahayakan kesehatan manusia (Suwaidah, dkk., 2014) Harapannya, usaha ini tidak hanya berhenti pada periode pendampingan saja, melainkan bisa menjadi salah satu sumber mata pencaharian pendukung bagi nelayan secara berkesinambungan.

Salah satu produk unggulan para istri nelayan daerah Nambangan yaitu ikan bulu ayam krispi. Ikan bulu ayam termasuk ikan pelagis kecil yang hidup di daerah pantai muara sungai dan membetuk gerombolan yang tidak begitu besar. Panjang ikan dapat mencapai panjang hingga $18 \mathrm{~cm}$ (kisaran umum 13-15 cm) (Rosana and Rifandi 2018). Sejak adanya pelatihan ini, para istri nelayan lebih terdorong untuk berfikir kreatif dan menciptakan produk-produk baru dan unik sehingga dapat menarik minat konsumen untuk membeli. Sebelumnya ikan bulu ayam hanya diolah menjadi ikan asin dengan nilai jual yang masih rendah namun sekarang hasil ide kreatif para istri nelayan, ikan bulu ayam diolah menjadi ikan bulu ayam krispi yang memiliki nilai jual lebih tinggi.

Produk unggulan lainnya yaitu ebi balado. Udang ebi adalah udang kecil yang diawetkan dengan cara dikeringkan, banyak digunakan sebagai bumbu masakan atau campuran racikan sayuran (Junaidi and Kurnianto 2016). Berbeda dengan pengelolaan ebi pada umumnya, para istri nelayan berinisiatif mengelola ebi menjadi kuliner nikmat menjadi lebih bernilai jual tinggi. Pada pelatihan ini para istri nelayan berhasil menyepakati nama produknya yaitu "KABONE" (Komunitas Bojone Nelayan). Nama tersebut bertujuan sebagai merek produk. pembeda produk istti nelayan dengan produk lainnya serta dapat lebih dikenal oleh konsumen. Selain itu para istri nelayan juga dapat meningkatkan kualitas kemasan produk menjadi lebih menarik. 


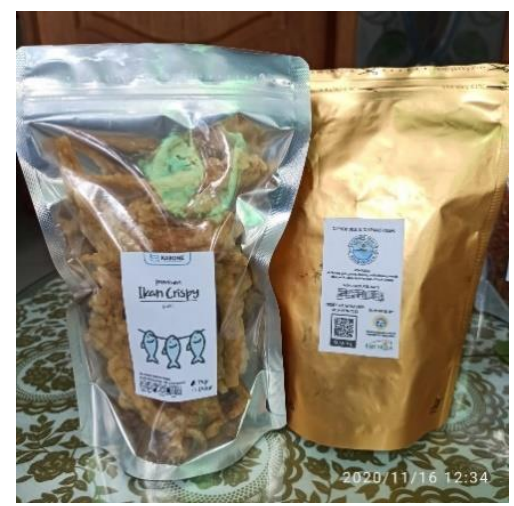

Gambar 3. Produk Hasil Repackaging

\section{Evaluasi}

Langkah evaluasi pelaksanaan program dan keberlanjutan program di lapangan setelah kegiatan pengmas selesai dilaksanakan adalah:

a. Tim pengabdian masyarakat terus memantau kegiatan usaha nelayan, apakah berjalan atau tidak; dan

b. Menyusun rencana program pengabdian masyarakat tahun berikutnya untuk pengembangan wilayah tersebut secara holistik.

Berdasarkan hasil observasi dan wawancara menunjukkan bahwa kegiatan ini berhasil memberikan perubahan peningkatan kemampuan para istri nelayan Kedungcowek dalam mengelola serta memasarkan hasil tangkapan laut. Selain itu adanya alat penunjang berupa freezer semakin memudahkan para istri nelayan menyimpan hasil olahan agar dapat bertahan hingga produk tersebut dibeli oleh para konsumen.

\section{PENUTUP}

\section{Simpulan}

Pendampingan Manajemen Pengolahan dan Pengawetan Ikan pada Istri Nelayan di Kelurahan Kedungcowek merupakan kegiatan yang penting dilakukan dalam rangka meningkatkan kesejahteraan keluarga nelayan. Kegiatan ini telah berhasil meningkatkan inovasi dalam mengelola hasil tangkapan laut para nelayan Kedungcowek menjadi lebih bernilai jual tinggi. Selain itu para istri nelayan Kedungcowek telah terlatih dalam memasarkan baik secara online maupun offline kepada konsumen secara langsung sehingga tidak bergantung lagi kepada para tengkulak. Pendapatan keluarga nelayan Kedungcowek menjadi lebih meningkat dari adanya kegiatan pengabdian masyarakat ini.

\section{Saran}

Saran yang bisa peneliti berikan pada kegiatan pengabdian masyarakat selanjutnya hendaknya diadakan pelatihan dalam rangka meningkatkan kreativitas para istri nelayan agar dapat mengolah ikan menjadi berbagai olahan makanan yang lebih inovatif serta dapat memanfaatkan berbagai marketplace sehingga sehingga dapat meluaskan jaringan konsumen. Selain itu, hendaknya para istri nelayan diberikan penyuluhan cara mendaftarkan produknya ke dinas kesehatan serta Majelis Ulama Indonesia. Sehingga kualitas produk terjamin dan dapat meningkatkan kepercayaan konsumen. Selain itu dibutuhkan kerjasama dengan Lembaga Keuangan Mikro untuk memberikan modal usaha kepada para Istri Nelayan Kedungcowek. 


\section{UCAPAN TERIMA KASIH}

Penulis menyampaikan terima kasih kepada Fakultas Ekonomi dan Bisnis, Universitas Airlangga atas Hibah Pengabdian Masyarakat Tahun Anggaran 2020, Koperasi 64 Bahari Surabaya dan Koperasi BMT Mandiri Ukhuwah Persada atas kerjasamanya dalam pelaksanaan kegiatan ini. Dalam penyusunan penelitian ini, penulis menyatakan bahwa tidak ada konflik kepentingan dengan pihak-pihak yang terkait dalam kegiatan pengabdian masyarakat ini.

\section{DAFTAR PUSTAKA}

Agusti, Fiqrie Restia, and Joko Wasisto. 2019. "Preservasi Manuskrip Di Upt Museum Sonobudoyo Sebagai Usaha Menjaga Eksistensi Budaya Di Yogyakarta." Jurnal Ilmu Perpustakaan 6(4): 251-60.

Agustin, Anes, Aprillia Intan Saputri, and Harianingsih Harianingsih. 2017. "Optimasi Pembuatan Karagenan Dari Rumput Laut Aplikasinya Untuk Perenyah Biskuit.” Jurnal Inovasi Teknik Kimia 2(2).

Badan Pusat Statistik. 2018. Statistik Sumber Daya Laut Dan Pesisir. Jakarta. https://www.bps.go.id/publication/2018/12/07/93a0fd8885fe2ac14201e71a/statisti k-sumber-daya-laut-dan-pesisir-2018.html.

Harminingtyas, Rudika. 2013. "Analisis Fungsi Kemasan Produk Melalui Model View Dan Pengaruhnya Terhadap Keputusan Pembelian Konsumen Pada Produk Rokok Kretek Merek DJI SAM SOE Di Kota Semarang." Jurnal STIE Semarang 5(2): 118.

Junaidi, J, and Rudi Kurnianto. 2016. "Rancang Bangun Alat Pengering Udang Ebi Tenaga Biomass Di Kecamatan Sungai Kunyit.” ELKHA: Jurnal Teknik Elektro $8(2): 5$.

Kurniawati, Andi. 2017. "Peran Istri Nelayan Dalam Rangka Meningkatkan Pendapatan Keluarga.” Jurnal Sains Dan Teknologi Maritim (1): 77-88.

Listyawati, Andayani. 2020. "Strategi Penanganan Kemiskinan Nelayan Tradisional." Media Informasi Penelitian Kesejahteraan Sosial 40(1): 61-70.

Nurjannah, Irma, and IMade Krisna Adhi Dahrma. 2019. "Tipologi Ruang Terbuka Publik Pada Kawasan Permukiman Nelayan Desa Bajo Indah.” Jurnal Malige Arsitektur (Media Arsitektur Lintas Generasi) 1(1): 8.

Puluhulawa, Julindri N, Asda Rauf, and Amir Halid. 2016. "Analisis Faktor-Faktor Yang Mempengaruhi Hasil Tangkapan Nelayan Di Kecamatan Bilato Kabupaten Gorontalo.” Agrinesia: Jurnal Ilmiah Agribisnis (1).

Retnowati, Endang. 2011. "Nelayan Indonesia Dalam Pusaran Kemiskinan Struktural (Perspektif Sosial, Ekonomi Dan Hukum).” Perspektif 16(3): 149-59.

Rosana, Nurul, and Safriudin Rifandi. 2018. "Rancang Bangun Dan Uji Coba Alat Pemanggil Ikan 'Piknet' Untuk Alat Tangkap Jaring Insang." Marine Fisheries: 
Wasiaturrahma, dkk: Peningkatan Pendapatan Nelayan Tradisional Melalui Pendampingan Manajemen Pengolahan dan Pengawetan Ikan Pada Istri Nelayan di Kelurahan Kedungcowek, Kecamatan Kenjeran, Surabaya

Journal of Marine Fisheries Technology and Management 9(2): 199-207.

Sucipto, Hadi. 2016. "Sistem Pendukung Keputusan Penentuan Jurusan Sekolah Menengah Atas Dengan Metode SAW." Sisfotenika 6(2): 146-57.

Suwaidah, Iis Siti, Nana Sutisna Achyadi, and Wisnu Cahyadi. 2014. "Kajian Cemaran Logam Berat Timbal Dari Kemasan Kertas Bekas Ke Dalam Makanan Gorengan." Nutrition and Food Research 37(2): 145-54.

Ulum, Miftahul et al. 2020. "Pengabdian Masyarakat Penyuluhan Perakitan Lampu Penerangan Bertenaga Surya Kepada Masyarakat Nambangan." Journal of Science and Social Development 3(1): 1-7.

Zebua, Yemima, Pradinda Krisna Wildani, Andika Lasefa, and Riki Rahmad. 2017. "Faktor Penyebab Rendahnya Tingkat Kesejahteraan Nelayan Pesisir Pantai Sri Mersing Desa Kuala Lama Kabupaten Serdang Bedagai Sumatera Utara." Jurnal Geografi 9(1): 88-98. 